\title{
Intimacy and Emotions. How Do Couples Express Positive and Negative Emotions
}

\author{
Milka Nicoleta Rotaru, Maria Nicoleta Turliuc and Simona Herb \\ Al.I.Cuza University, Iași, Romania
}

\begin{abstract}
Intimacy has long been a research point of interest as couples therapy and family interactions have come to the attention of psychology studies. A theoretical perspective with practical implications, offering a detailed understanding of the concept is the interpersonal model of intimacy. Self-disclosure and partner response, as well as the associated emotions are main aspects of the model and are considered in the present study. 98 participants have responded to items referring to positive and negative emotions in the relationship they are involved in. Gender difference, strategies used by men and women in expressing both positive and negative emotions and categories of emotions identified by both genders have been analysed and discussed.
\end{abstract}

Keywords: emotions, intimacy, interpersonal relationships, self-disclosure, partner response

\section{Theoretical backgrounds}

\subsection{The interpersonal model of intimacy}

There are few topics that have received more attention in individual, couple and family therapeutic settings and interventions than the expression of intimacy and emotions (Keltner \& Lerner, 2010). However, studies with a clear focus on these constructs have first been of a general type. Intimacy and emotions are psychological constructs studied in a vast array of social and interpersonal settings and different types of research, but only in recent years have they been part of studies referring to dyadic relationships. Moreover, they have been seen as part of psychological models where expressions of emotions are directly connected to intimacy and the progression of a positive attitude towards the marital relationship (Finkel \& Vohs, 2006).

The underlining theoretical background refers to Reis \& Shaver's interpersonal intimacy level (Reis \& Shaver, 1988), which assumes that intimacy is built in interpersonal relationships through two complementary processes: self-disclosure and the emphatic response of the partner, both including emotions (Mitchell, Castellani, Herrington., Joseph, Doss \& Snyder, 2008) This model offers a detailed understanding of the concept of intimacy, with multiple facets, having temporal traits and assuring clear guiding lines in what concerns the definition and measurement of intimacy (Laurenceau, Rivera, Schaffer \& Pietromonaco, 2004).

Intimacy starts through the verbalisation of thoughts, emotions, feelings and other significant aspects by one of the partners and continues with an adequate verbal response of the listener, that shows understanding and involvement in the conversation. It is essential that the partner perceives the interest and empathy of the listener, but also the fact that he/she cares for what has been shared (Laurenceau, Barrett \& Rovine, 2005).

Self- disclosure refers to communicating information and emotions that are relevant for the person who discloses. Self- disclosure has been accountable for half of intimacy's variance in empirical studies. It may refer to factual or descriptive aspects, as well as emotional or cognitive ones (Reis \& Shaver, 1988). Although both factual and emotional self-disclosure reveal aspects regarding the self, emotional self-disclosure, both verbal and non-verbal, is closer to the experience of intimacy, because it facilitates access to the essential elements of the Ego, to understanding them and to validation from the partner (Laurenceau et al., 2004).

The mediating mechanism is, as the interpersonal model of intimacy shows, the perceived response from the partner, which suggests to the speaker that he/ she is appreciated and valued. The roles are permanently changing in couple interaction and, as the Ego of each partner is expressed and validated by the other, the intimacy between them grows ${ }^{1}$ In order to contribute to the increase of intimacy, the perceived response from the partner must be based on sincere care for the other, must be immediate and must refer to the content expressed by the speaker and address the need of the speaker. 


\subsection{Emotions and dyadic relationships}

Emotions are a psychological process that gives direction to individuals in what concerns our position in the world and our future actions. The process includes a very rapid perception of the importance of things, followed by a somatic response and a cognitive effort of understanding and planning an action.

Emotions are described as distinct and consistent responses to internal and external events which have a certain significance for the body. They have a short duration and consist of a coordinated set of responses, which might include verbal, physiological and behavioural mechanisms (Elaine, 2008).

But do men and women experience emotions in a similar manner? Do they manifest emotions in different ways or is just the frequency and intensity of these emotions different?

At a first look, there is a common hypothesis that women are more sensitive and express more emotions than men. There are several studies that address this question and tend to support the above conclusion, when discussing the emotional expression capacity in men and women, but also the fact that there are emotions manifested especially by men and especially by women.

During the last decade, there has been an increase of research that have had as an aim the examination of the connection between emotions and gender. The traditional approach - which gender is more emotional and which is the connection between gender and depression- prevailed, but was sustained by research from a modern mind set- the connection between gender stereotypes, beliefs about emotions and how emotions operate in real life (Robinson, Johnson \& Shields, 1998).

There are emotional expressions accepted for both genders and emotions that have been assumed to be relevant for only one gender. For instance, being sad, depressed, fearful and embarrassed are seen as non-manly attributes and men who express these emotions are negatively evaluated compared to the women expressing these emotions. By contrast, anger and aggressiveness are seen as acceptable for men, not for women.

Aggressive boys are considered to be more pleasant and socially adapted than those who do not manifest aggressiveness ${ }^{2}$, whereas aggressive girls are evaluated as being less pleasant and less adapted from a social point of view. This is one of the reasons women learn to repress their aggressiveness, which will lead to a bigger degree of anxiety, tension and panic attacks ( Hart, DeWolf, \& Burts, 1993).

Taking all these into account, can there be contexts and motives for trespassing barriers in emotional expression? Clark and Finkel (2005) bring forth different types of relationships in which we are engaged at a certain point and their impact on our availability of expressing our emotional universe. The authors mention previous studies in which there are distinct relationships (Clark. \& Mills, 1993).

- exchange relationships, in which a partner offers something to the other as a response to benefiting already offered or with the expectation of a reward in the future;

- communion relationships, that refer to offering unconditional benefits to the partner, as a response to his needs or in order to show care towards him.

An important premise used by Clark and Finkel (2005) is that individual differences should influence the expression of emotions. Two studies which research the link between attachment styles and emotional expressions in marital and non-marital dyads are mentioned.

\section{The Present Study}

The primary aim of the present study is to explore the characteristics of positive and negative emotions in couples. It addresses general questions, but also specific ones, such as:

- identifying, naming and ordering positive and negative emotions, by their importance, in intimate couple/ family relationships;

- describing adequate manners of expressing such emotions to one's partner;

- justifying the need to express these emotions and why it is important for a partner to know these emotions. 
A secondary aim is to explore whether a spontaneous order found in the enumeration of emotions is the same as the order attributed to these emotions in the context of evaluating their importance, together with calculating a coefficient which shows the relative importance of these emotions.

\subsection{Method}

\subsubsection{The role of the researcher}

Interpreting data in qualitative research will always be subject to limitations caused by the conductor of the study. There is no expected influence regarding the categories of emotions addressed in the present study, but there is an expected influence from the researcher in what concerns the methods of expression and the importance attributed to expressing emotions. There is a much bigger possibility of subjectivity.

The most common method used to minimize negative effects of this aspect refers to the involvement of two researchers who will analyse and confront the categories. This is also the method chosen for the present study. The derived categories have been analysed individually and afterwards confronted and discussed.

\subsubsection{Participants}

Identifying and recruiting participants was done with the strategy of sampling criteria. Studies show that this type of sampling has benefits in developing new and useful theories in order to assure quality, as all cases in the study conform to a series of well-established criteria. The questionnaire was offered with the following instructions:

- The participants have been part throughout their life in a relationship of minimum 6 months and at present are involved in such a relationship, official or non-official;

- Participants will have to be in two age categories: 20-30 years old and 30-40 years old, both genders.

The total number of valid collected questionnaires was 98 and the respondents to the study had the

following characteristics:

- The average age was 26.49 years (minimal age of 20 years and maximum age of 45 years);

- Very few respondents have children (the average is smaller than 1);

- Most of them are unmarried but involved in relationships (63\%), only $25 \%$ are married and the remaining rest are single, but have been previously involved in a minimum of 6 months relationship;

- The average relationship duration is 65.33 months (around 5.4 years), denoting the fact that, although unmarried, many respondents have had a long relationship;

- The average cohabitation length is 32,54 years (less than 3 years);

- $56 \%$ of participants have higher education, whereas $18 \%$ have postgraduate degrees and $23 \%$ of participants middle education.

- $58.2 \%$ of participants have been females, with an average age of 25.16 years and most of which are single, but involved in a relationship (68.4\%); only $17.5 \%$ are married and the rest are at present single.

- For women, the average length of the relationships is 59,98 months (around 5 years) and the average cohabitation length is 26.93 months ( around 2.2 years);

- $\quad 64.9 \%$ of women have higher education, $12.3 \%$ postgraduate degrees and $21.1 \%$ have middle education (most of them are students and are, thus, in the process of achieving a higher education degree).

- $41.8 \%$ participants are men with an average age of 28.34 years (the minimum age of male participants is 20 years and the maximum age is 43 years);

- Most men are at present unmarried, but involved in a relationship (58.5\%); 36.6\% are married and the rest are single;

- For men, the average relationship length is 72.76 months (around 6 years, bigger than the average length of the entire sample, but influenced by the fact that one third of men are married, whereas only one forth of female participants are married);

- The average cohabitation length is also larger for males (40.59 months, around 3.3 years);

- $43.9 \%$ of men have higher education degrees, $26.8 \%$ postgraduate degrees and $26 \%$ middle education.

\subsection{Instruments}

The main instrument used in this study is a qualitative questionnaire referring to: 
- 5 most frequent positive emotions expressed towards the partner and the hierarchy as importance in the life of the partners

- 5 most frequent negative emotions expressed towards the partner and the hierarchy as importance in the life of the partners

- Data regarding the gender of the participants and information regarding the relationship.

In order to collect a large amount of data and considering the reticence of respondents when it comes to free discussions about their private lives, we preferred an open questions questionnaire, in a paper and pen format, but also an electronic format, depending on the preferences of the participants. A tendency of men to prefer the electronic variant of the questionnaire was observed, which could be a manifestation of the need to be sure of their confidentiality and separated from their response, thus showing a great social desirability tendency.

All participants have been informed about the aim of the study and had the option of accessing the results after the collected data was analysed.

\subsection{Analysis}

The main strategies used in analysing data are frequency analysis and analysis of the relative importance of emotions, by attributing theme codes to text fragments which suggest comparable themes with what research literature has already identified in similar studies about the expression of emotions in dyadic relationships.

In this phase of the study it is premature to aim at creating a model. The aim should better be that of identifying elements specific to the Romanian population, by comparing results with those obtained by similar studies in different cultural contexts, with reference to the main elements of emotion centred therapy. Results of previous research are meant to guide, support and create a basis for the analysis of theoretical results of the present study.

\section{a. The first level of analysis: summarizing and coding data}

Facilitating the analysis of data and creating a batch of well-organized texts was a primary step towards the analysis and it meant introducing data in a database and attributing theme codes by selecting fragments of text that was suitable to the general significance of the text of a certain code.

\section{b. The second level of analysis: data aggregation}

This stage of the analysis means identifying subcategories and key models, or possible relationships between the selected data, in order to generate models or smaller groupings of data that could be considered sub-topics of the major research topics.

In order to interpret information referring to the expression of emotions, the interpretation was done in a perpetual parallel with already reported data in the present literature. This is why some tags applied to concepts and themes which have been identified by us have been chosen to reflect what is already known in the international literature, especially with reference to the vocabulary of emotions specific to emotion centred therapy.

In what negative and positive emotions are concerned, the analysis of frequency is enriched by calculating a relative importance of these, determined by the degree which the participants have given to these emotions subsequent to their enumeration.

The analysis and processing of the data was done using SPSS 19.0 and MAXQDA11, a specific instrument for thematic analysis.

\subsection{Results}

\subsubsection{Positive emotions}

The register of positive emotions that are recognized by the participants to the study as being specific to dyadic relationships is presented in the table below. 
TABLE I: The most frequent positive emotions

\begin{tabular}{|c|c|c|c|}
\hline Primary emotion & Secondary emotion & Tertiary emotion & Frequency \\
\hline \multirow{10}{*}{ Joy (186) } & \multirow[t]{3}{*}{ Pride (35) } & Pride & 6 \\
\hline & & Thankfulness & 11 \\
\hline & & Respect & 18 \\
\hline & Thankfulness (4) & Gratification & 4 \\
\hline & Verve (12) & Enthusiasm & 12 \\
\hline & \multirow{5}{*}{ Joyfulness (82) } & Cheer & 2 \\
\hline & & Delight & 4 \\
\hline & & Satisfaction & 5 \\
\hline & & Happiness & 30 \\
\hline & & Joy & 41 \\
\hline \multirow{13}{*}{ Love (178) } & \multirow{11}{*}{ Affection (160) } & Affection & 4 \\
\hline & & Attraction & 5 \\
\hline & & Friendship & 6 \\
\hline & & Empathy & 7 \\
\hline & & Appreciation & 7 \\
\hline & & Understanding & 9 \\
\hline & & Admiration & 13 \\
\hline & & Safety & 16 \\
\hline & & Trust & 22 \\
\hline & & Love & 31 \\
\hline & & Crush & 40 \\
\hline & \multirow[t]{2}{*}{ Sensuality (18) } & Corporal sensations & 4 \\
\hline & & Passion & 14 \\
\hline
\end{tabular}

We hereby find two primary emotions of the three found in emotion centred therapy- love and joy- but we did not find surprise, which is more difficult to identify. Of the total of 478 words and expressions mentioned by the participants of our studies, we retained for the analysis using thematic codes a number of 371 words, over $77 \%$ of the generated words.

Of the secondary and tertiary emotions associated to the primary one, respect is the centre of the generated expressions, which correlates with the need of the individual to feel valuable. Although frequent, a lot of emotions occupy a less important quadrant for the individual. Joy and happiness are often mentioned, but are not as important as respect. Actually, joy as a secondary or tertiary emotion cannot appear without respect.

Less frequent and less important are emotions such as pride, tranquillity, which are logical responses considering that there are other main ingredients which bring joy to the partners.

A similar analysis for love as a primary emotion discloses the following. Love is central to the participants of the study, together with trust, passion and admiration- an interpreter of sensuality, which contributes to the quality of couple satisfaction. Less frequent and less important are appreciation and empathy.

The comparative distribution shows differences in what concerns the most important five enumerated emotions. We must, however, keep in mind that the male participants to the study are fewer as a number and, most importantly, are more mature, married, involved in a stable long standing relationship and somehow inclined to more social desirable responses in what concerns emotional expressions and its role in couple relationships.

Men value love, whereas women tend to have greater frequency of happiness and joy. Emotions such as safety, enthusiasm and affection are mostly written by women, while passion is mostly considered by men. This is an apparent confirmation of the stereotype which focuses women on affection and men on physical activity.

\subsubsection{Negative emotions}

In what concerns negative emotions, contrary to expectations, all three categories of primary emotions are represented and almost all important sub-topics. From 301 words retained for analysis, sadness prevails and anger, as a primary emotion, is rarely found in the answers of the respondents. 


\begin{tabular}{|c|c|c|c|}
\hline $\begin{array}{l}\text { Important and frequent } \\
\text { emotions } \\
\text { - Love (40-1.3) } \\
\text { - Passion (14-2.07) } \\
\text { - Admiration } \\
\text { - } 2.46) \\
\text { - Trust (22-1.9) }\end{array}$ & $\begin{array}{l}\text { Frequent and } \\
\text { unimportant emotions } \\
\begin{array}{ll}\text { - } & \text { Safety (16-3.25) } \\
\text { - } & \text { Understanding } \\
& (9-2.88)\end{array}\end{array}$ & $\begin{array}{l}\text { Important and frequent } \\
\text { emotions } \\
\quad \text { - Respect }(18-2.5)\end{array}$ & 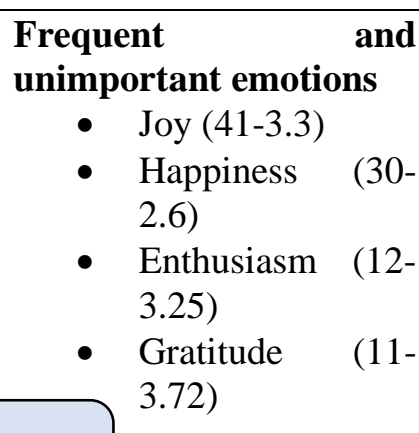 \\
\hline $\begin{array}{l}\text { Less frequent but } \\
\text { important emotions }\end{array}$ & $\begin{array}{l}\text { Less frequent and } \\
\text { unimportant emotions } \\
\text { - Appreciation (7- } \\
\text { 2.85) } \\
\text { - Empathy (7-2.71) }\end{array}$ & $\begin{array}{l}\text { Less frequent but } \\
\text { important emotions }\end{array}$ & $\begin{array}{l}\text { Less frequent and } \\
\text { unimportant emotions } \\
\text { - Pride }(6-3.5) \\
\text { - Tranquillity } \\
\quad 4.8)\end{array}$ \\
\hline
\end{tabular}

Fig. 1: Full representation of love and joy as the main positive basic emotion

TABLE II: The most frequent negative emotions

\begin{tabular}{|c|c|c|c|}
\hline Primary emotions & Secondary emotion & Tertiary emotion & Frequency \\
\hline \multirow[t]{4}{*}{ Fear (47) } & \multirow[t]{4}{*}{ Nervousness (47) } & Unrest & 3 \\
\hline & & Concern & 13 \\
\hline & & Nervousness & 14 \\
\hline & & Fear & 17 \\
\hline \multirow[t]{7}{*}{ Anger (100) } & \multirow[t]{3}{*}{ Exasperation (55) } & Hate & 4 \\
\hline & & Frustration & 20 \\
\hline & & Anger & 31 \\
\hline & \multirow[t]{2}{*}{ Envy (32) } & Envy & 5 \\
\hline & & Jealousy & 27 \\
\hline & Irritation (10) & Rampage & 10 \\
\hline & Bitterness (3) & Ego & 3 \\
\hline \multirow[t]{14}{*}{ Sadness (154) } & \multirow[t]{2}{*}{ Disappointment (23) } & Dissatisfaction & 8 \\
\hline & & Disappointment & 15 \\
\hline & \multirow[t]{6}{*}{ Neglect (49) } & Inferiority & 4 \\
\hline & & Misunderstanding & 7 \\
\hline & & Recklessness & 6 \\
\hline & & Indifference & 8 \\
\hline & & Shortage & 10 \\
\hline & & Distrust & 14 \\
\hline & \multirow[t]{2}{*}{ Shame (17) } & Regret & 7 \\
\hline & & Guilt & 10 \\
\hline & Suffering (7) & Stress & 7 \\
\hline & \multirow[t]{3}{*}{ Sadness (60) } & Boredom & 9 \\
\hline & & Sorrow & 25 \\
\hline & & Sadness & 26 \\
\hline
\end{tabular}

Therefore, in the centre of sadness as an emotion we can find distrust and sorrow. If sorrow is somehow diffuse- anything from a partner's behaviour could cause it- distrust as a central emotion confirms the validity of the model propose by emotion centred therapy. Guilt and disappointment have a higher frequency, but their importance in the dynamics of the relationship is much more reduced compared to sorrow and distrust.

When discussing the second category of primary negative emotions, that is fury, only seven tertiary emotions are kept, afferent to secondary emotions. The negative dominant emotion is not anger in its self as might be expected considering its high frequency, but jealousy and frustration. 
Anger as a primary emotion is more difficult to identify, but the sources it has are easier to find- jealousy, frustrations associated to divergences, positional differences etc. Envy, often confused with jealousy doesn't occupy a central role, nor does hate- they are rarely mentioned and have different peripheral positions in the hierarchies constructed by the respondents.

\begin{tabular}{|c|c|c|c|}
\hline $\begin{array}{l}\text { Important and frequent } \\
\text { emotions } \\
\text { - Jealousy (27- } 1.8) \\
\text { - Frustration } \\
\quad \text { 1.6) }\end{array}$ & $\begin{array}{c}\text { Frequent and } \\
\text { unimportant emotions } \\
\qquad \quad \text { Anger }(31-2.58)\end{array}$ & $\begin{array}{l}\text { Important and frequent } \\
\text { emotions } \\
\text { - Concern } \\
\text { - } 1.78) \\
\text { Worry }(13-2.38)\end{array}$ & $\begin{array}{l}\text { Frequent and } \\
\text { unimportant emotions } \\
\qquad \quad \text { Fear }(17-3.17)\end{array}$ \\
\hline ANC & ER & $\mathbf{F E}$ & $A R$ \\
\hline $\begin{array}{l}\text { Less frequent but } \\
\text { important emotions }\end{array}$ & $\begin{array}{cc}\text { Less } & \text { frequent and } \\
\text { unimportant emotions } \\
\text { - } \quad \text { Envy }(5-3.4) \\
\text { - Hate }(4-4.5)\end{array}$ & $\begin{array}{l}\text { Less frequent but } \\
\text { important emotions }\end{array}$ & $\begin{array}{c}\text { Less frequent and } \\
\text { unimportant emotions } \\
\bullet \quad \text { Unrest }(3-3.67)\end{array}$ \\
\hline
\end{tabular}

Fig. 2: Full representation of anger and fear

Last, but not least, fear distributes its four associated emotions in the following manner: fear is especially associated with irritation, which is actually determined by fear at a behavioural level, but also with worrying, which is understood as expressing care for the partner and for the relationship. Fear is frequent but evaluated as less important- people try to convince themselves they do not have reasons to be afraid and, although they recognize it as a frequent negative emotion, they also tend to "sweeten" its effects, considering it should be on a tertiary level.

\subsection{Discussion}

Analysing gender differences shows that men have expressed fewer emotions. In the case of positive emotions there have been categories where men have expressed more emotions than women, but in the case of negative emotions, there is no category in which men expressed more words than women.

How can we explain the tendency to recognize and admit fewer emotions by men and especially in what concerns negative emotions? Is it a defence mechanism or should we be talking about alexytimia?

The real challenge of thematic analysis and identifying suggestive codes has been clear in the context of analysing different expressions the 98 participants have used when answering questions about the appropriate manner of expressing positive and negative emotions they just enumerated.

Apparently, direct verbal expressions represent the most adequate manner of conveying positive emotions, but does it refer to convenient answers people think they should express? The second most appreciated manner of conveying emotions has been considered to be touching, with all its forms (kissing, caressing, touching, holding hands). The third most important one is surprising one's partner and offering gifts, which could show the influence of some social pressures.

When it comes to negative emotions, there is no great difference, as individuals assert they can transmit directly what they do not like regarding their partner and their relationship, although communication has a different valency. A special category, verbal aggressiveness, appears more often than crying, which suggests that contradictory discussions are regarded as having a more negative significance in the relationship than pure expressions of emotions.

Another interesting aspect is avoiding the partner or stopping of communication, a common punishment method that assumes the punished partner will understand the negative emotion without being verbally expressed. The consequence of this strategy is actually a self-punishment, as the negative emotion remains unsaid and becomes of greater intensity. 
All in all, positive and negative emotions are a very important part of daily lives of couples and they can be perceived differently by the partners. Verbal and non-verbal communicating strategies are subject to gender influences, whereas positive and negative emotions have specific embodiments in the relationship with reference to the background of individuals.

The study of emotions and their expression in the daily life of couples is still uncharted territory and we are just at the beginning of mapping the interactions and strategies used in order to express emotions and how these influence intimacy.

\section{Acknowledgements}

This work was co-funded by the European Social Fund through Sectoral Operational Programme Human Resources Development 2007 - 2013, project number POSDRU/187/1.5/S/155397, project title "Towards a New Generation of Elite Researchers through Doctoral Scolarships.”

\section{References}

[1] “Emotion”, D. Keltner \& J.S. Lerner in The handbook of social psychology, 5th ed., New York, NY: Wiley, 2010, Vol. 1, pp. 317-347, S.T. Fiske, D.T. Gilbert, \& G. Lindzey (Eds.).

[2] "Introduction: Intrapersonal processes, interpersonal relationships", E.J. Finkel, \& K.D.Vohs in "Self and relationships: Connecting intrapersonal and interpersonal processes" K. D. Vohs, \& E. J. Finkel (Eds.), New York: Guilford, 2006, pp. 1-9. http://dx.doi.org/10.3366/edinburgh/9780748624621.003.0001

[3] „Intimacy as an interpersonal process”, H.T. Reis \& P. R. Shaver, in "Handbook of research in personal relationships", Duck, S. (Ed.), London, England: Wiley, 1988, pp. 367-389.

[4] A.E. Mitchell, A. M. Castellani, R.L. Herrington., J. I. Joseph, B. D. Doss \& D. K. Snyder, "Predictors of intimacy in couples' discussions of relationship injuries: An observational study", Journal of Family Psychology, Vol 22(1), Feb: 21-29, 2008. http://dx.doi.org/10.1037/0893-3200.22.1.21

[5] "Intimacy as an interpersonal process: Current status and future directions", J-P. Laurenceau, L.M. Rivera, A.Schaffer, \& P.R. Pietromonaco, in "Handbook of closeness and intimacy", D. Mashek, \& A. Aron (Eds.), NJ: Lawrence Erlbaum, Mahwah ,2004, pp. 61-78.

[6] J-P. Laurenceau, L.F. Barrett \& M.J. Rovine, "The interpersonal process model of intimacy in marriage: A daily-diary and multilevel modeling approach" in Journal of Family Psychology, 2005, 19, p. 314-323.

http://dx.doi.org/10.1037/0893-3200.19.2.314

[7] Idem

[8] „Intimacy as an interpersonal process”, H.T. Reis \& P. R. Shaver, in "Handbook of research in personal relationships", Duck, S. (Ed.), London, England: Wiley, 1988, pp. 367-389.

[9] "Intimacy as an interpersonal process: Current status and future directions", J-P. Laurenceau, L.M. Rivera, A.Schaffer, \& P.R. Pietromonaco, in "Handbook of closeness and intimacy", D. Mashek, \& A. Aron (Eds.), NJ: Lawrence Erlbaum, Mahwah, 2004, pp. 61-78.

[10] "Emotion Science: An Integration of Cognitive and Neuroscientific Approaches”, F. Elaine, New York: Palgrave MacMillan, 2008.

[11] M.D. Robinson, J.T. Johnson \& S.A. Shields, "The gender heuristic and the database: Factors affecting the perception of ender-related differences in the experience and display of emotions", Basic and Applied Social Psychology, 1998, 20, 206-219.

http://dx.doi.org/10.1207/s15324834basp2003_3

[12] "Parental disciplinary strategies and preschoolers' play behavior in playground settings", C.H. Hart, M.DeWolf, \& D.C. Burts, in "Children on playgrounds: Research perspectives and applications", C. H. Hart (Ed.), Albany: State University of New York Press, 1993, pp. 271-3 13.

[13] M.S. Clark. \& J. Mills, "The difference between communal and exchange relationships: What it is and is not", Personality and Social Psychology Bulletin, 19, 684-691, 1993. http://dx.doi.org/10.1177/0146167293196003

[14] M.S. Clark \& E.J. Finkel, "Willingness to express emotion: The impact of relationship type, communal orientation, and their interaction", Personal Relationships, 12, 169-180, 2005.

http://dx.doi.org/10.1111/j.1350-4126.2005.00109.x 